\section{Removal of a migrated gastric band using the Soehendra bile stone lithotripter}

A rare but disturbing complication of the placement of a laparoscopy-assisted gastric band (LAGB) is luminal migration into the stomach $[1,2]$. Although there are various techniques described to remove a migrated band, most require expensive or specialized equipment, which is not always readily available [3-5]. Herein, we present a novel, simple and effective technique that was used to remove a migrated gastric band using the Soehendra lithotripter.

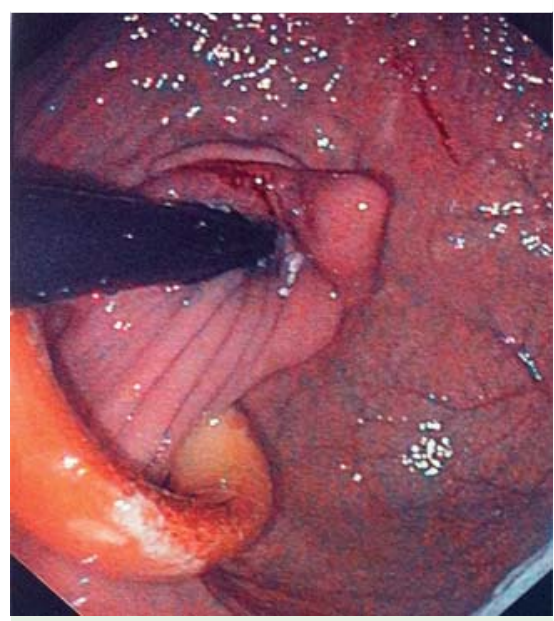

Fig. 1 Endoscopic view of the gastric band that was found to have partially migrated into the stomach 12 years after laparoscopy-assisted placement.
A 58-year-old man had undergone LAGB placement 12 years previously. An esophagogastroduodenscopy (EGD) performed for dyspepsia revealed that the LAGB had partially migrated into the stomach ( $\bullet$ Fig. 1). The removal procedure was carried out in the operating room and the following six steps were performed to remove the migrated band: (i) the surgeon released the subcutaneous port; (ii) during EGD, a wire (Metro; Cook, WinstonSalem, North Carolina, USA) was placed around the band ( $\mathrm{Fig} .2$ ); (iii) both ends of the wire were pulled out of the mouth ( $\nabla$ Fig.3a); (iv) the wire was inserted into the lithotripter cable ( Fig.3b,c); (v) the lithotripter was advanced into the stomach and tightened around the band ( Fig.4); (vi) the wire and lithotripter cable were tightly pulled around the band using the traditional stone lithotripsy technique, which resulted in the band being successfully transected ( $\mathbf{F i g . 4}$; - Video 1). The band was then removed with a snare ( $\bullet$ Fig.5).

To the best of our knowledge, this is the first report of successful endoscopic removal of a LAGB using a Soehendra lithotripter. Our method is interesting because it shows that standard instruments such as biliary wires and lithotripters can be used to transect an elastic band, so allowing its successful removal and sparing the

\section{Video 1}

The wire and lithotripter cable were tightly pulled around the band using the traditional stone lithotripsy technique, which resulted in successful transection of the migrated gastric band.
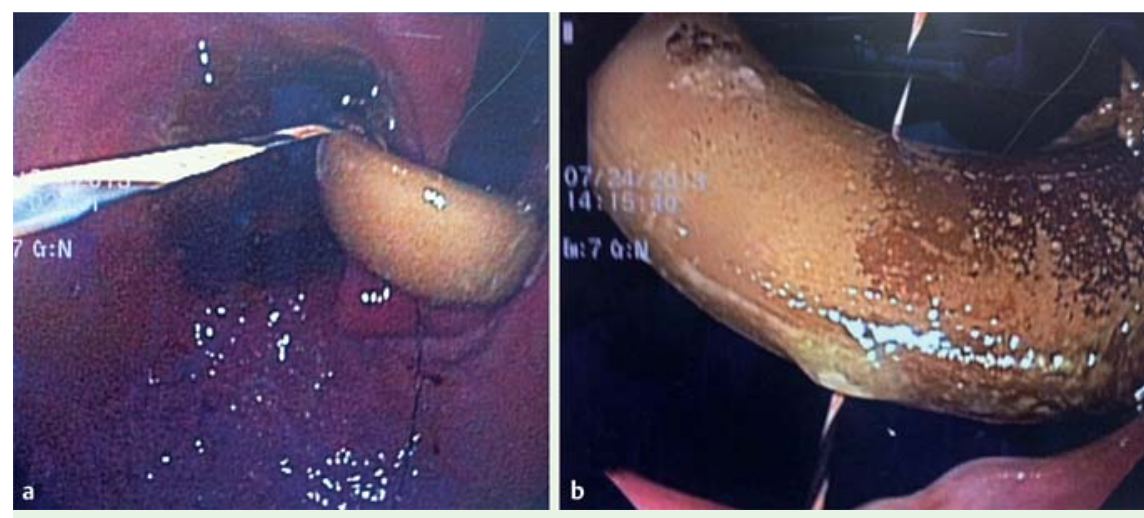

Fig. 2 Endoscopic views showing: a the wire being advanced into the stomach and beyond the gastric band; $\mathbf{b}$ the wire positioned around the band.
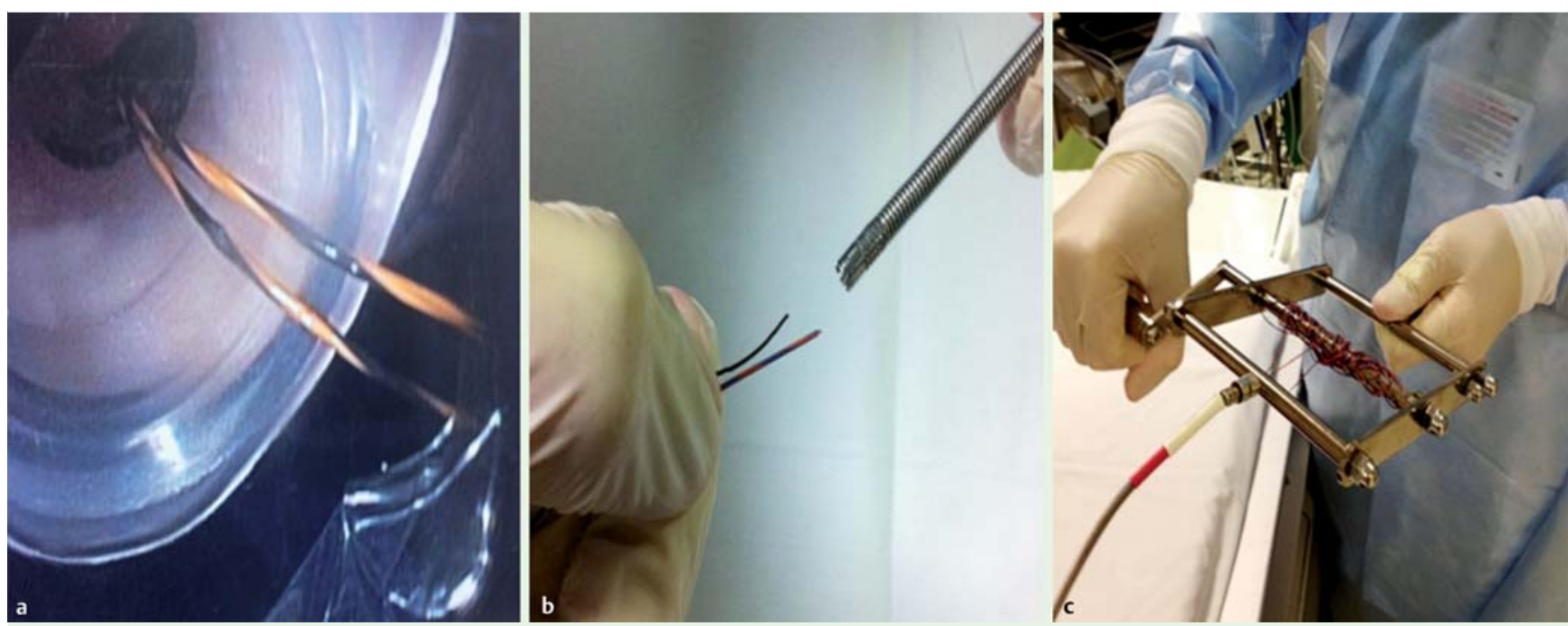

Fig. 3 Photographs of the procedure showing: a both ends of the wire being pulled out of the mouth; $\mathbf{b}$ the wire being fed through the lithotripter cable shaft; c the wire attached to the crank handle. 

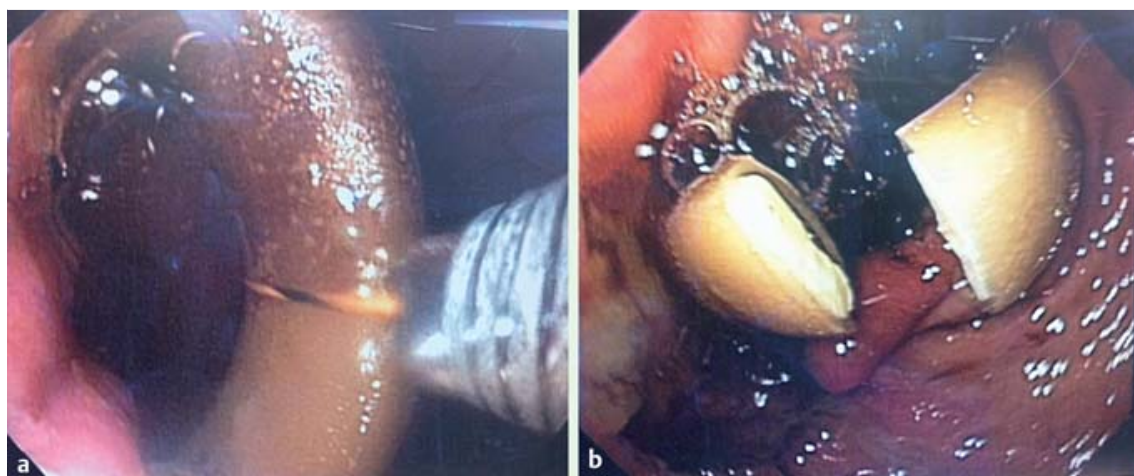

Fig. 4 Endoscopic views showing: a the wire as it is tightened around the band by slowly rotating the lithotripter handle; $\mathbf{b}$ the transected band.

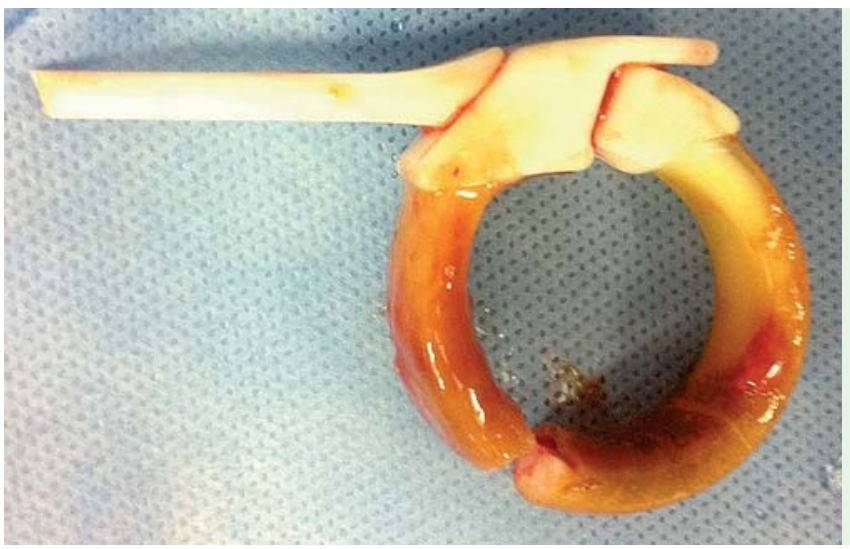

patient from undergoing an invasive surgical procedure. The equipment used in our method is readily available in any advanced endoscopy suite. We believe that this technique should be added to the armamentarium of the therapeutic endoscopist because, with the current obesity epidemic, we anticipate that more endoscopic procedures will be required to treat complications such as the one presented here.
Fig. 5 Photograph of the gastric band following its transection and removal.

\section{References}

1 Chiu CJ, Birch DW, Shi X et al. Outcomes of the adjustable gastric band in a publicly funded obesity program. Can J Surg 2013; 56: $233-236$

2 Carbajo Caballero MA, Martín del Olmo JC, Blanco Alvarez JI et al. Intragastric migration of laparoscopic adjustable gastric band (Lap-Band) for morbid obesity. J Laparoendosc Adv Surg Tech A 1998; 8: $241-244$

3 Coskun H, Bozkurt S, Atak T et al. Endoscopic management of penetrated adjustable gastric band with its connecting tube: report of a case. Obes Facts 2011; 4: 244-247

4 Rogalski P, Hady HR, Baniukiewicz A et al. Gastric band migration following laparoscopic adjustable gastric banding (LAGB): two cases of endoscopic management using a gastric band cutter. Wideochir Inne Tech Malo Inwazyjne 2012; 7: 114-117

5 Chen Yi, Mei SG, Tam W et al. Endoscopic removal of migrating silastic band after vertical banding gastroplasty. Endoscopy 2010; 42 (Suppl. 02): E253

\section{Bibliography}

DOI http://dx.doi.org/

10.1055/s-0033-1344798

Endoscopy 2013; 45: E371-E372

(c) Georg Thieme Verlag KG

Stuttgart · New York

ISSN 0013-726X

\section{Corresponding author}

\section{rez, MD}

Endoscopy_UCTN_Code_TTT_1AO_2AL

Competing interests: None

Hospital Italiano

Bulevar Artigas 1632

Montevideo 11300

Uruguay

Fax: +598-2-4812505

Juan P. Gutiérrez, Fernando Acosta, Hector Geninazzi, Horacio Gutiérrez Galiana

Department of Clinical Gastroenterology, Hospital Italiano, Montevideo, Uruguay 